\title{
DIDS INHIBITION OF SARCOPLASMIC RETICULUM ANION EFFLUX AND CALCIUM TRANSPORT
}

Kevin P. Campbell and David H. MacLennan

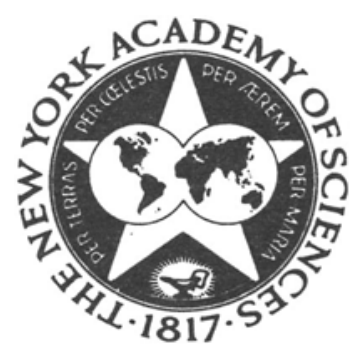

Reprinted from ANNALS OF THE NEW YORK ACADEMY OF SCIENCES Volume 358 Pages 328-331

December 23,1980 28031 


\title{
DIDS INHIBITION OF SARCOPLASMIC RETICULUM ANION EFFLUX AND CALCIUM TRANSPORT
}

\author{
Kevin P. Campbell and David H. MacLennan \\ Banting and Best Department of Medical Research \\ University of Toronto \\ Toronto, Ontario \\ Canada M5G 1 L6
}

Sarcoplasmic reticulum vesicles have been shown to take up large amounts of calcium when the incubation medium is supplemented with calcium-precipitating anions such as oxalate or phosphate. ${ }^{1}$ Calcium is taken up in approximately stoichiometric amounts with oxalate or phosphate, although calcium uptake always exceeds anion uptake by a small amount. ${ }^{1}$ The passive anion permeability of the sarcoplasmic reticulum is very high, ${ }^{2}$ but the mechanism and the pathway of anion transport is not known.

The disulfonic stilbenes are potent and specific inhibitors of anion transport in red blood cells and several other cellular systems, but they have little or no effect on cation permeability. ${ }^{3}$ 4,4'-Diisothiocyano-2,2'-stilbene disulfonic acid (DIDS), an irreversible inhibitor of anion transport in red blood cells, has been used to identify Band 3 as the anion transport protein. ${ }^{3}$ Recently, Kasai and Kometani ${ }^{4}$ have used light scattering to show that 4-acetoamido-4'isothiocyano-stilbene-2,2'-disulfonate (SITS) inhibits anion permeability in sarcoplasmic reticulum vesicles.

DIDS was found to inhibit $\left[{ }^{32} \mathrm{P}\right]$ phosphate and $\left[{ }^{14} \mathrm{C}\right]$ oxalate efflux from isolated sarcoplasmic reticulum vesicles with no effect on calcium efflux (FIGURE 1). Half-maximal inhibition of phosphate efflux occurred at $\simeq 3 \mu \mathrm{M}$ DIDS. Complete inhibition of phosphate or oxalate efflux required approximately $50 \mu \mathrm{M}$ DIDS.

DIDS was also found to be a potent inhibitor of calcium transport in sarcoplasmic reticulum vesicles (FIGURE 2). Half-maximal inhibition of $\mathrm{Ca}^{2+}$ transport in the presence of oxalate or phosphate occurred at $\simeq 4 \mu \mathrm{M}$ DIDS and $\mathrm{Ca}^{2+}$ transport was completely inhibited by $\simeq 12 \mu \mathrm{M}$ DIDS. Inorganic phosphate competed with DIDS and reduced the inhibition of $\mathrm{Ca}^{2+}$ transport due to low concentrations of DIDS $(\simeq 2 \mu \mathrm{M})$. Comparison of DIDS inhibition of $\mathrm{Ca}^{2+}$ transport in the presence of various anions showed that DIDS inhibition of $\mathrm{Ca}^{2+}$ transport was dependent on the permeability of the anion in the medium. At $4 \mu \mathrm{M}$ DIDS (where phosphate and oxalate efflux were inhibited by $50 \%$ ), $\mathrm{Ca}^{2+}$ transport in the presence of oxalate or phosphate was inhibited by $\simeq 50 \%$; in the presence of $\mathrm{Cl}^{-}$, an anion of high permeability, DIDS inhibited $\mathrm{Ca}^{2+}$ transport by $\simeq 15 \%$; and in the presence of $\mathrm{SCN}^{-}$, a lipid-permeable anion, DIDS only inhibited by $5 \%$. This implies that DIDS inhibition of $\mathrm{Ca}^{2+}$ transport is through its inhibition of anion transport. DIDS also inhibited $\mathrm{Ca}^{2+}$ uptake by $50 \%$ at a concentration of $12 \mu \mathrm{M}$ in vesicles reconstituted with purified $\mathrm{Ca}^{2+}$-ATPase. Inhibition occurred in spite of high internal oxalate so that anion transport was not essential for $\mathrm{Ca}^{2+}$ precipitation within the vesicles. At $\mathrm{pH}$ 6.8, DIDS inhibition of $\mathrm{Ca}^{2+}$ transport was independent of the time of preincubation of the vesicles with DIDS and could be reversed by the addition 

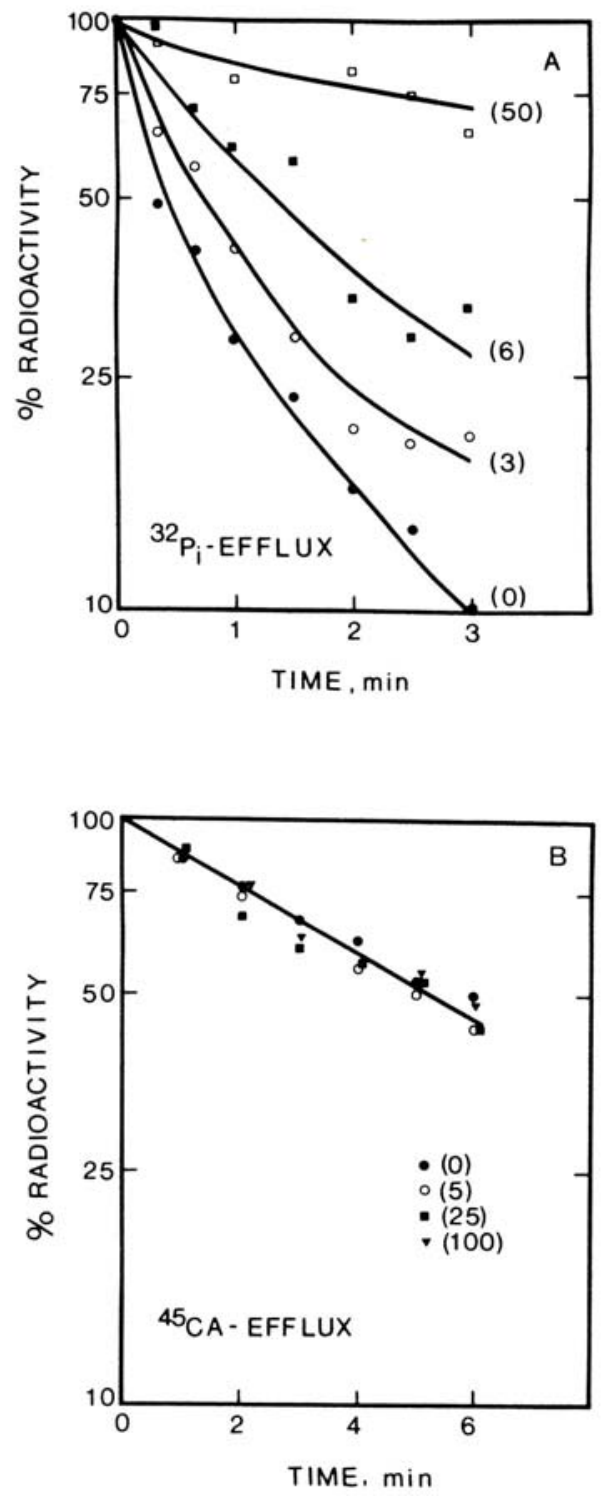

FIGURE 1. Effect of DIDS on ion efflux from sarcoplasmic reticulum vesicles. Vesicles were equilibrated for $40 \mathrm{hr}$ at $0^{\circ} \mathrm{C}$ with (A) $1 \mathrm{mM}^{32} \mathrm{P}_{\mathrm{i}}$ or (B) $0.5 \mathrm{mM}{ }^{45} \mathrm{Ca}$ in the presence of $100 \mathrm{mM} \mathrm{KCl}, 5 \mathrm{mM} \mathrm{MgCl}_{2}, 20 \mathrm{mM}$ histidine ( $\mathrm{pH} 6.8$ ), $0.5 \mathrm{mM}$ $\mathrm{CaCl}_{2}$, and $0.5 \mathrm{mM}$ EGTA [ethylene glycol bis $\left(\beta\right.$-aminoethylether)- $N, N, N^{\prime}, N^{\prime}$-tetraacetic acid]. They were then diluted 400 -fold into a medium of identical composition but containing no radioisotopes. Exchange rates were determined at $23{ }^{\circ} \mathrm{C}$ by Millipore filtration. Percent radioactivity remaining in the vesicles was plotted against time for various concentrations of DIDS in the dilution medium. DIDS concentration $(\mu \mathrm{M})$ is indicated in parenthesis. 


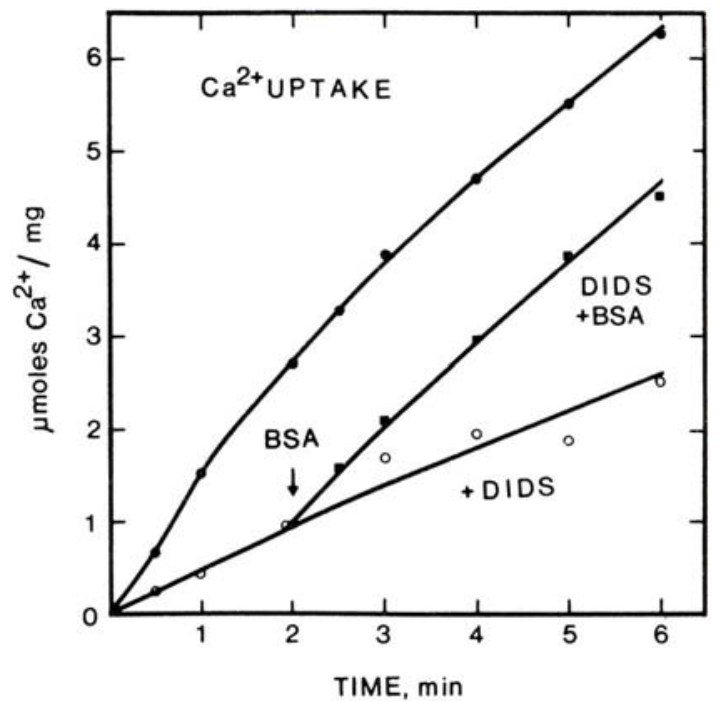

FIGURE 2. Reversible inhibition of sarcoplasmic reticulum calcium transport by DIDS as $\mathrm{pH}$ 6.8. $\mathrm{Ca}^{2+}$ uptake was measured at $20 \mathrm{Mg} / \mathrm{ml}$ in the presence of $100 \mathrm{mM}$ $\mathrm{KC1}, 5 \mathrm{mM} \mathrm{MgCl} 2,20 \mathrm{mM}$ histidine (pH 6.8), $50 \mathrm{mM} \mathrm{PO}_{4}{ }^{2-}, 0.5 \mathrm{mM}^{45} \mathrm{CaCl}_{2}, 0.5 \mathrm{mM}$ EGTA, and $5 \mathrm{mM}$ ATP, using Millipore filtration. DIDS $(6 \mu \mathrm{M})$ was added to the reaction medium just prior to the addition of sarcoplasmic reticulum vesicles. DIDS inhibition of calcium uptake was reversed by the addition of $5 \mathrm{mg} / \mathrm{ml}$ BSA (fatty-acidfree) at $1.5 \mathrm{~min}$.

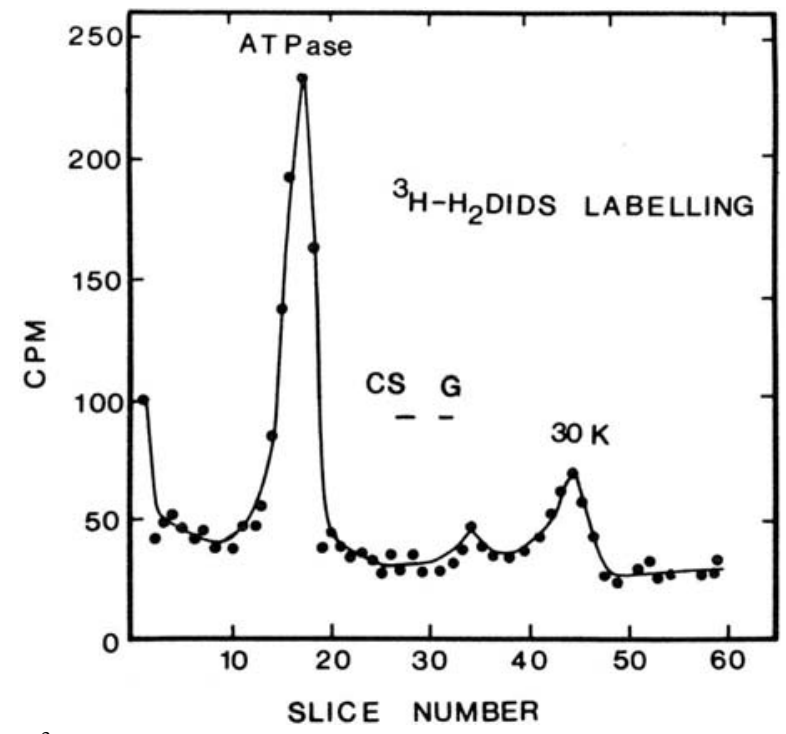

FIGURE 3. $\left[{ }^{3} \mathrm{H}\right] \mathrm{H}_{2}$ DIDS labeling of sarcoplasmic reticulum vesicles. Vesicles were labeled with $10 \mu \mathrm{M}\left[{ }^{3} \mathrm{H}\right] \mathrm{H}_{2} \mathrm{DIDS}$ at $\mathrm{pH} 8.0$ for $20 \mathrm{~min}$ at $37^{\circ} \mathrm{C}$. They were subsequently washed three times with BSA and proteins were separated by SDS gel electrophoresis. $\left[{ }^{3} \mathrm{H}\right] \mathrm{H}_{2}$ DIDS-labeled proteins were identified following gel slicing and counting. ATPase, CS (calsequestrin), G (instrinsic glyeoprotein), and the $30 \mathrm{~K}$ region are indicated. The rate of $\mathrm{Ca}^{2+}$ uptake in the $\left[{ }^{3} \mathrm{H}\right] \mathrm{H}_{2}$ DIDS-labeled vesicles was inhibited by $35 \%$ when compared to control vesicles. 
of fatty-acid-free BSA (5 mg/ml) (FIGURE 2). At pH 8.0, DIDS bound irreversibly to the vesicles and inhibited $\mathrm{Ca}^{2+}$ transport. Upon analysis of $\left[{ }^{3} \mathrm{H}\right] \mathrm{H}_{2}-$ DIDS-labeled vesicles by SDS gel electrophoresis, radioactivity was found to be associated predominantly with the $\mathrm{Ca}^{2+}$-ATPase (FIGURE 3 ).

DIDS inhibition of calcium transport in sarcoplasmic reticulum vesicles could occur through inhibition of the active site of the $\left(\mathrm{Ca}^{2+}+\mathrm{Mg}^{2+}\right)$-ATPase or through inhibition of an anion transport component in the sarcoplasmic reticulum. Our results indicate that DIDS inhibits the anion permeability of sarcoplasmic reticulum vesicles at very low concentrations $(2-6 \mu \mathrm{M})$ and that this inhibition is probably responsible for inhibition of calcium uptake when phosphate or oxalate are required for calcium transport. At higher concentrations of DIDS $(8-12 \mu \mathrm{M})$ calcium transport is also inhibited when anion transport is not necessarily involved in calcium transport. DIDS could be acting on the ATPase active site in this concentration range or the ATPase might be tightly coupled to anion transport, so that inhibition of anion transport inhibits the $\mathrm{Ca}^{2+}$ transport indirectly.

\section{REFERENCES}

1. Hasselbach, W. 1979. The sarcoplasmic calcium pump. A model of energy transduction in biological membranes. Top. Curr. Chem. 78:1-56.

2. Meissner, G. \& D. MCKinley. 1976. Permeability of sarcoplasmic reticulum membrane. The effect of changed ionic environments on $\mathrm{Ca}^{2+}$ release. J. Membr. Biol. 30:79-98.

3. CabantchiK, Z. I., P. A. Knauf \& A. Rothstein. 1978. The anion transport system of the red blood cell. The role of membrane proteins evaluated by the use of "probes." Biochim. Biophys. Acta 515:239-302.

4. Kasai, M. \& T. Kometani. 1979. Inhibition of anion permeability of sarcoplasmic reticulum vesicles by 4 -acetoamido-4'-isothiocyano-stilbene-2,2'-Disulfonate. Biochim. Biophys. Acta 557:243-247. 